\title{
ASPEK MORFOLOGI, REPRODUKSI, DAN PERILAKU PENYU HIJAU (Chelonia mydas) Di PANTAI PANGUMBAHAN, KABUPATEN SUKABUMI, JAWA BARAT
}

\author{
Adriani Sri Nastiti Krismono1), Achmad Fitriyanto1), dan Ngurah Nyoman Wiadnyana ${ }^{2)}$ \\ 1) Peneliti pada Balai Riset Pemulihan Sumber Daya Ikan, Jatiluhur-Purwakarta \\ 2) Peneliti pada Balai Riset Perikanan Perairan Umum, Mariana-Palembang \\ Teregistrasi I tanggal: 14 Mei 2010; Diterima setelah perbaikan tanggal: 20 Juli 2010; \\ Disetujui terbit tanggal: 30 Juli 2010
}

\begin{abstract}
ABSTRAK
Penyu hijau (Chelonia mydas) termasuk dalam phylum Chordata dan famili Cheloniideae. Jumlah penyu hijau yang singgah ke Pantai Pangumbahan untuk bertelur semakin menurun karena tidak terkendalinya masyarakat melakukan penangkapan induk penyu dan pengambilan telurnya. Penelitian tentang morfologi, reproduksi, dan perilaku penyu hijau sebagai salah satu dasar pengelolaan telah dilakukan di Pantai Pangumbahan pada bulan Agustus 2008. Metode penelitian yang digunakan pengambilan contoh berstrata. Penelitian ini dilaksanakan pada bulan Agustus 2008 (pada saat puncak peneluran). Parameter yang diamati antara lain ukuran penyu dari 89 ekor jumlah penyu bersarang, jumlah telur dan tingkat penetasan, serta perilaku pada saat penyu bertelur. Hasil penelitian menunjukan yang diamati diperoleh panjang karapas berkisar antara 97-15 cm dan lebar karapas 83,5-108 cm, jumlah penyu naik ke pantai 89 ekor dan penyu yang bertelur 39 ekor. Jumlah telur penyu hijau berhasil dihitung 80-105 butir per induk penyu. Bulan Agustus 2008 merupakan puncak musim peneluran. Kegiatan peneluran penyu hijau dibagi menjadi enam tahap. Upaya konservasi yang sudah dilakukan adalah penetasan telur penyu semi alami, restocking tukik, dan menjaga keamanan sarang telur penyu.
\end{abstract}

KATA KUNCI: $\quad$ morfologi, reproduksi, perilaku, penyu hijau, Pantai Pangumbahan

ABSTRACT: $\quad$ Morphology, reproduction, and behaviour aspects of green turtle (Chelonia mydas) in Pangumbahan Beach, Sukabumi Regency, West Java. By: Adriani Sri Nastiti Krismono, Achmad Fitriyanto, and Ngurah Nyoman Wiadnyana

Green turtles (Chelonia mydas), including the phylum Chordata and families Cheloniideae. The number of green turtles come to lay eggs Pangumbahan beach to decline because of increasingly unmanageable public do making arrests turtles brood stock and their eggs. Research on the morphology, reproduction, and behavior of green turtles as one of the basic management has been conducted on the Pangumbahan Beach in August 2008. The method used stratified sampling. The experiment was conducted in August 2008 (at the peak of nesting). Other parameters were observed between the size of the 89 tail number of turtles nesting turtles, the number of eggs and hatching rate and behavior during turtle nesting. Results obtained showed that the observed length ranges from 97$15 \mathrm{~cm}$ carapace and carapace width from $83.5-108 \mathrm{~cm}$, the number went up to the beach 89 sea turtle and sea turtle nesting tail as much as 39 tails. The number of green turtle eggs had counted as many as 80-105 eggs per turtles brood stock. Month August 2008 is the peak nesting season of green turtle nesting activities are divided into six stages. Conservation efforts that have been done is semi natural turtle hatchery, restocking hatchlings, and nest of turtle eggs to maintain security.

KEYWORDS: $\quad$ morphology, reproduction, behaviour of green turtle, Pangumbahan beach 


\section{PENDAHULUAN}

Pantai Pangumbahan memiliki panjang 2,8 km dan luas 115 ha, terletak pada ketinggian 2,50 m dari permukaan laut. Secara administratif, termasuk dalam Desa Gunung Batu, Kecamatan Ciracap, Kabupaten Sukabumi. Pantai Pangumbahan merupakan habitat peneluran penyu hijau (Chelonia mydas) yang sangat sesuai dan merupakan satu kesatuan dengan daerah pantai penyu yang terdapat di Suaka Margasatwa Cikepuh yaitu Pantai Citireum, Hujungan dan Cibulakan, serta gosongan batu karang dan cadas yang terdapat di Pantai Batu Namprak (Anonimus, 2008). Selain penyu hijau di Pantai Pangumbahan juga dijumpai penyu belimbing namun jumlahnya hanya sedikit bila dibandingkan dengan penyu hijau, bahkan jarang dijumpai lagi (Adnyana, 2006). Sejak tahun 1979 pantai Pangumbahan dikenal sebagai habitat peneluran penyu hijau dan telah dikelola oleh swasta. Menurut Yudha (2004) jumlah penyu yang singgah di Pantai Pangumbahan pada tahun 2003-2004 mengalami peningkatan. Selama bulan Januari sampai Juli 2003 (bukan musim bertelur) rata-rata kehadiran penyu hijau hanya mencapai 2-3 ekor/malam/bulan sedangkan pada bulan yang sama tahun 2004 mencapai 3-6 ekor/malam/bulan, musim bertelur berlangsung antara bulan Agustus sampai Desember dan pada tahun 2003 tercatat penyu hijau yang hadir mencapai 4-12 ekor/malam/bulan. Pada puncak musim bertelur, seekor induk penyu dapat menghasilkan telur 80-200 butir sekali bertelur. Jumlah telur yang dapat menetas maksimal antara $70-75 \%$ selanjutnya jumlah tukik hanya tersisa kurang dari $1 \%$ yang dapat bertahan sampai dewasa dan dapat bertelur kembali.

Menurut Purwa (2010) di dunia terdapat tujuh jenis penyu, enam jenis penyu di antaranya terdapat di perairan Indonesia yang berasal dari dua famili yang berbeda yaitu Cheloniideae dan Dermochelideae. Enam jenis penyu tersebut adalah penyu belimbing (Leatherback turtle/Dermochelys coriache), penyu hijau (Green turtle/Chelonia mydas), penyu sisik (Hawksbill turtle/Eretmochelys imbricata), penyu tempayan (Loggerhead turtle/Caretta caretta), penyu lekang (Olive ridley turtle/Lepidochelys olivacea), dan penyu pipih (Flatback turtle/Natator depresus). Penyu tempayan ditemukan tersebar di seluruh Indonesia. Dari enam jenis tersebut penyu hijau diketahui bertelur di pantai selatan Jawa Barat. Salah satu ciri dari kawasan tempat bertelur penyu hijau adalah adanya vegetasi pandan di pantai, kemungkinan besar peteluran penyu di pantai yang ditumbuhi vegetasi pandan ini merupakan strategi perlindungan bagi telur penyu hijau. Oleh karena itu, pengambilan daun pandan oleh masyarakat yang digunakan sebagai bahan baku anyaman merupakan gangguan bagi peteluran penyu hijau (Wahyudin, 2004).

Dalam perdagangan dunia Internasional semua jenis penyu tersebut telah terancam dan telah termasuk dalam daftar IUCN Red List dengan kategori endangered spesies, sedangkan dalam CITES dicantumkan dalam Appendix Iyang artinya dilarang diperdagangkan secara Internasional.

Permasalahan yang terjadi pada saat ini adalah semakin menurunnya populasi penyu hijau di Pantai Pangumbahan karena adanya penangkapan induk penyu dan pengambilan telur penyu yang tidak terkendali karena seluruh organ tubuh penyu termasuk telur yang dihasilkan mempunyai nilai ekonomis tinggi. Menurut data dari Dinas Perikanan dan Kelautan Kabupaten Sukabumi terjadi kecenderungan penurunan jumlah telur penyu pada musimnya setiap tahun. Jumlah telur yang dihasilkan tahun 2001 mencapai 15.000 butir diikuti pada tahun 2002 mencapai 10.000 butir, tahun 2004 mencapai 12.000 butir, dan tahun 2007 menurun menjadi 10.000 butir (Dinas Kelautan dan Perikanan Kabupaten Sukabumi, 2008).

Tujuan penelitian ini adalah untuk mendapatkan gambaran secara deskriptif tentang biologi, reproduksi, dan perilaku penyu hijau sebagai salah satu dasar pengelolaan konservasi penyu hijau di Pantai Pangumbahan.

\section{BAHAN DAN METODE}

\section{Lokasi dan Waktu Penelitian}

Pantai Pangumbahan dengan panjang 2,8 km terbagi menjadi enam pos pengamatan penyu. Pantai Pangumbahan termasuk dalam Desa Gunung Batu, Kecamatan Ciracap, Kabupaten Sukabumi. Secara geografis, Pantai Pangumbahan terletak pada 7¹7'08"-7²1'50" LS dan 106²3'40"-106²4'10" BT (Gambar 1). Penelitian ini dilaksanakan pada bulan Agustus 2008 bersamaan dengan musim penyu hijau bertelur.

\section{Cara Pengumpulan Data}

Data dan Informasi primer yaitu aspek biologi penyu hijau dikumpulkan dari enam pos pengunduhan.Beberapa parameter biologi yang diamati disajikan pada Tabel 1. Informasi sekunder yang diperoleh dari studi pustaka dan penelusuran melalui kantor Dinas Perikanan dan Kelautan Kabupaten Sukabumi dan instansi terkait. 


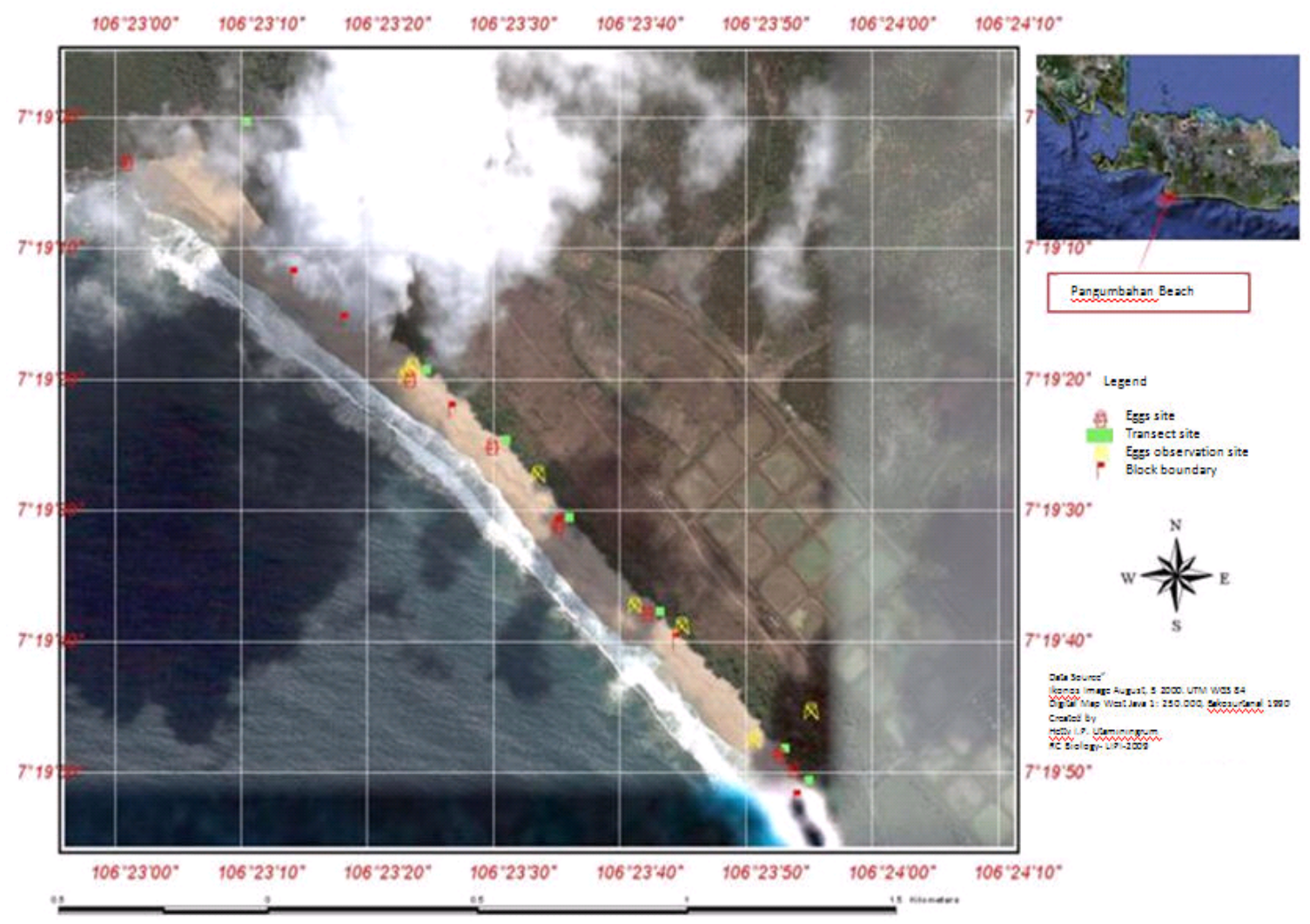

Gambar 1. Lokasi pengamatan penyu hijau di Pantai Pangumbahan, Kabupaten Sukabumi, Jawa Barat. Figure 1. Observatian location of green turtles in Pangumbahan beach, Sukabumi regency, West Java.

Sumber/Sources: Nastiti et al. (2009)

Tabel 1. Pengukuran parameter dan metode yang digunakan

Table 1. Parameter measured and methods used

\begin{tabular}{cll}
\hline No. & \multicolumn{1}{c}{ Parameter/Parameters } & \multicolumn{1}{c}{ Metode/Method } \\
\hline 1. & Kondisi umum lokasi penelitian & Pengamatan langsung insitu dan penelusuran pustaka \\
2. & Kehadiran penyu hijau & Penghitungan visual insitu \\
3. & Fluktuasi jumlah telur penyu hijau & Penghitungan visual insitu \\
4. & Morfologi penyu hijau & Pengamatan langsung insitu \\
5. & Morfometri penyu hijau & Meteran, $\mathrm{CCL}^{*}$ dan $\mathrm{CCW}^{*}$ insitu, Caliper insitu \\
6. & Perilaku penyu hijau dalam proses bertelur & Pengamatan langsung, kamera, jam insitu \\
\hline
\end{tabular}

Keterangan/Remarks: ") CCL (Curve Carapace Length: panjang lengkung karapas); CCW (Curve Carapace Width)

\section{HASIL DAN BAHASAN}

\section{Kehadiran Penyu Hijau dan Fluktuasi Jumlah Telur Penyu Hijau}

Kehadiran penyu hijau di pantai erat kaitannya dengan proses reproduksi. Pengamatan dilakukan pada Agustus 2008 yaitu bertepatan dengan awal musim penyu hijau bertelur. Naiknya induk penyu ke tempat sarang atau tempat bertelur dipengaruhi oleh kondisi pantai yang cocok sebagai habitat peneluran. Penyu hijau merupakan hewan yang sensitif terhadap getaran, memiliki kemampuan melihat obyek yang ada di depannya sampai sudut 30 dan $180^{\circ}$ ke arah samping serta dapat berakomodasi dengan baik pada sudut $150^{\circ}$ serta cahaya dengan panjang gelombang $520 \mathrm{~nm}$ (biru hijau) (Bustard, 1972 dalam Nuitja, 1992). Kondisi yang terjadi pada saat pengamatan, di pantai Pangumbahan banyak dikunjungi oleh wisatawan. Mereka memperlakukan penyu yang sedang mencari sarang peteluran sebagai suatu hiburan. Pengelola di daerah tersebut belum siap dengan peraturan untuk melindungi induk penyu hijau dari gangguan baik oleh manusia ataupun kegiatan lain. Pengamatan pada 
bulan Agustus 2007 menunjukan jumlah penyu yang naik ke daratan dan jumlah bertelur meningkat pada akhir bulan (Tabel 2). Dari Tabel tersebut diketahui hasil pencatatan pada tanggal 28-30 Agustus 2008. Induk penyu yang tidak berhasil bertelur akan kembali lagi ke laut. Menurut Hirth, 1971 dalam Nuitja (1992) kemampuan penyu untuk kembali lagi ke pantai tempat asal penyu dilahirkan dipengaruhi oleh sifat khas penyu yang homing orientation.

Tabel 2. Kehadiran penyu hijau di Pantai Pangumbahan, bulan Agustus 2008

Table 2. Green turtle absent in Pangumbahan Coast, August 2008

\begin{tabular}{|c|c|c|c|c|c|c|c|}
\hline $\begin{array}{c}\text { Tanggal/ } \\
\text { Date }\end{array}$ & $\begin{array}{c}\text { Jumlah } \\
\text { penyu yang } \\
\text { naik ke } \\
\text { pantai/ } \\
\text { Total of } \\
\text { turtle at } \\
\text { Pangumbahan } \\
\text { coast }\end{array}$ & $\begin{array}{c}\text { Jumlah } \\
\text { penyu } \\
\text { yang } \\
\text { bertelur/ } \\
\text { Total } \\
\text { spawn }\end{array}$ & $\begin{array}{c}\text { Jumlah } \\
\text { telur } \\
\text { penyu/ } \\
\text { Total } \\
\text { eggs }\end{array}$ & $\begin{array}{c}\text { Tanggal/ } \\
\text { Date }\end{array}$ & $\begin{array}{c}\text { Jumlah } \\
\text { penyu yang } \\
\text { naik ke } \\
\text { pantai/ } \\
\text { Total of } \\
\text { turtle at } \\
\text { Pangumbahan } \\
\text { coast }\end{array}$ & $\begin{array}{c}\text { Jumlah } \\
\text { penyu } \\
\text { yang } \\
\text { bertelur/ } \\
\text { Total of } \\
\text { spawn }\end{array}$ & $\begin{array}{c}\text { Jumlah } \\
\text { telur } \\
\text { penyu/ } \\
\text { Total eggs }\end{array}$ \\
\hline 01.08 .2008 & 5 & 1 & 112 & $\begin{array}{ll}16.08 .2008 \\
\end{array}$ & 14 & 7 & 721 \\
\hline 02.08 .2008 & 5 & 2 & 200 & 17.08 .2008 & 11 & 5 & 470 \\
\hline 03.08.2008 & 8 & 3 & 264 & 18.08 .2008 & 12 & 7 & 678 \\
\hline 04.08.2008 & 12 & 5 & 509 & 19.08 .2008 & 15 & 7 & 733 \\
\hline 05.08.2008 & 12 & 7 & 711 & 20.08.2008 & 16 & 8 & 885 \\
\hline 06.08.2008 & 6 & 2 & 230 & 21.08 .2008 & 16 & 9 & 979 \\
\hline 07.08.2008 & 9 & 4 & 383 & 22.08.2008 & 13 & 6 & 602 \\
\hline 08.08.2008 & 5 & 2 & 177 & 23.08 .2008 & 12 & 8 & 715 \\
\hline 09.08.2008 & 11 & 6 & 571 & 24.08.2008 & 13 & 8 & 831 \\
\hline 10.08.2008 & 8 & 4 & 380 & 25.08 .2008 & 16 & 9 & 945 \\
\hline 11.08 .2008 & 10 & 6 & 547 & 26.08.2008 & 14 & 8 & 839 \\
\hline 12.08 .2008 & 12 & 6 & 571 & 27.08 .2008 & 13 & 7 & 735 \\
\hline 13.08.2008 & 10 & 5 & 452 & 28.08 .2008 & 36 & 15 & 1615 \\
\hline 14.08.2008 & 10 & 5 & 560 & 29.08 .2008 & 26 & 10 & 1098 \\
\hline \multirow[t]{2}{*}{15.08 .2008} & 13 & 7 & 710 & 30.08 .2008 & 27 & 14 & 1211 \\
\hline & & & & 31.08 .2008 & 32 & 16 & 958 \\
\hline
\end{tabular}

Jumlah telur penyu yang ditetaskan secara semi alami pada tahun 2007-2008 mulai meningkat pada tahun 2008. Pada tahun 2007 jumlah telur yang menetas 1.558-4.148 butir (50\%) dan pada tahun 2008 telur menetas semua $100 \%$ (Tabel 3). Sejak bulan April 2008 pengelolaan kawasan peneluran penyu hijau di Pantai Pangumbahan diserahterimakan dari pihak swasta kepada pemerintah setempat (Dinas Perikanan dan Kelautan Kabupaten Sukabumi) dan selanjutnya oleh pemerintah dicalonkan menjadi Kawasan Konservasi Laut Daerah.

Tabel3. Persentase telur penyu hijau yang ditetaskan

Table 3. Percentage of green turtle's egg hatched

\begin{tabular}{|c|c|c|c|c|c|c|c|c|c|}
\hline $\begin{array}{c}\text { Tahun/ } \\
\text { Year }\end{array}$ & $\begin{array}{l}\text { Bulan/ } \\
\text { Month }\end{array}$ & $\begin{array}{c}\text { Jumlah } \\
\text { telur yang } \\
\text { dihasilkan/ } \\
\text { Total eggs }\end{array}$ & $\begin{array}{c}\text { Jumlah } \\
\text { telur yang } \\
\text { ditetaskan/ } \\
\text { Total eggs } \\
\text { spawning }\end{array}$ & $\%$ & $\begin{array}{c}\text { Tahun/ } \\
\text { Year }\end{array}$ & $\begin{array}{l}\text { Bulan/ } \\
\text { Month }\end{array}$ & $\begin{array}{c}\text { Jumlah } \\
\text { telur yang } \\
\text { dihasilkan/ } \\
\text { Total eggs }\end{array}$ & $\begin{array}{c}\text { Jumlah telur } \\
\text { yang } \\
\text { ditetaskan/ } \\
\text { Total eggs } \\
\text { spawning } \\
\end{array}$ & $\%$ \\
\hline \multirow{12}{*}{2007} & Januari & 9.558 & $\mathrm{td}$ & Td & 2008 & Januari & 2.634 & 1.256 & 48 \\
\hline & Pebruari & 4.227 & td & $\mathrm{Td}$ & & Pebruari & 2.162 & 1.050 & 49 \\
\hline & Maret & 3.868 & td & $\mathrm{Td}$ & & Maret & 2.698 & 2.624 & 97 \\
\hline & April & 2.944 & td & $\mathrm{Td}$ & & April & 2.793 & 2.793 & 100 \\
\hline & Mei & 4.225 & 2.113 & 50 & & Mei & 2.929 & 2.929 & 100 \\
\hline & Juni & 5.832 & 2.916 & 50 & & Juni & 2.710 & 2.710 & 100 \\
\hline & Juli & 4.509 & 2.255 & 50 & & Juli & 2.299 & 2.299 & 100 \\
\hline & Agustus & 3.056 & 1.528 & 50 & & Agustus & 20.412 & 20.412 & 100 \\
\hline & September & 4.409 & 2.205 & 50 & & September & 37.785 & 37.785 & 100 \\
\hline & Oktober & 6.170 & 3.085 & 50 & & & & & \\
\hline & Nopember & 8.295 & 4.148 & 50 & & & & & \\
\hline & Desember & 6.530 & 3.265 & 50 & & & & & \\
\hline
\end{tabular}




\section{Morfologi dan Ukuran Penyu Hijau}

Penyu hijau, memiliki ciri-ciri khusus antara lain karapas berwarna kuning kehijauan atau coklat kehitam gelap dengan cangkang berbentuk bulat telur (bila dilihat dari atas) kepalanya relatif kecil dan tumpul.

Hasil pengukuran terhadap 18 ekor penyu diperoleh panjang karapas penyu hijau di pantai Pangumbahan berkisar antara $97-115 \mathrm{~cm}$ dan lebar karapas berkisar antara 83,5-108 cm (Gambar 3). Menurut Nuitja (1992) pada umumnya besar dan kecilnya ukuran karapas penyu dapat digunakan untuk mengetahui populasi umur penyu dan juga berpengaruh pada ukuran dan jumlah telur penyu yang di hasilkan. Semakin tua umur induk penyu maka semakin besar juga ukuran telur yang dihasilkan dan jumlah telur juga semakin banyak. Hal tersebut juga dipengaruhi oleh berbagai faktor, misalnya kondisi lingkungan yang tidak stabil, rusaknya habitat penyu, eksploitasi besar-besaran, dan lain-lain. Pada Gambar 3 secara matematik, menunjukan bahwa panjang karapas dipengaruhi oleh lebar karapas.

Power

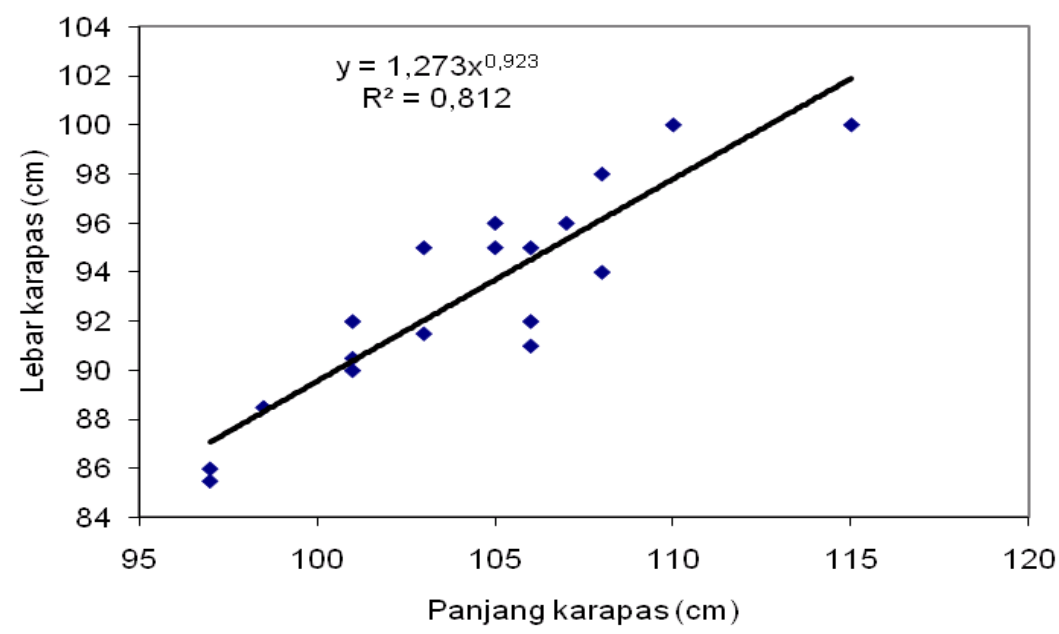

Gambar 3. Hubungan panjang dan lebar karapas penyu di Pantai Pangumbahan, bulan Agustus 2008. Figure 3. The relation of length and width of green turtle in Pangumbahan coast, August 2008.

Pengenalan kelamin penyu dapat dilihat dari bentuk ekornya. Pada usia muda sangat sulit dikenal jenis kelaminnya karena memiliki bentuk ekor yang sama. Penyu jantan memiliki ekor yang lebih panjang dan bentuk kepalanya lebih menyempit dibandingkan penyu betina. Telur penyu berbentuk elip (elliptical) atau bulat (spherical) berwarna putih dengan memiliki kulit telur yang kenyal. Menurut Nuitja (1992) ukuran telur penyu mempunyai korelasi dengan jenis penyu yang bertelur. Diameter telur berkisar antara $44-46$ $\mathrm{mm}$ dengan bobot telur sekali berkisar antara $50-52$ g. Seekor induk penyu hijau bertelur antara 80-105 butir. Telur ditetaskan dengan sistem semi alami, yaitu telur diinkubasi selama $45-60$ hari dalam wadah yang telah diisi pasir tujuannya agar suhu tetap terjaga sekitar $33^{\circ} \mathrm{C}$ sehingga akan mempercepat penetasan telur yang menghasilkan tukik (bayi penyu) sekitar $96-100 \%$ (Tabel 4).

Tabel 4. Jumlah tukik hasil penetasan telur penyu hijau di Pangumbahan, tahun 2008 Table 4. Total of hutchling in Pangumbahan coast in 2008

\begin{tabular}{lccc}
\hline Bulan/Month & $\begin{array}{c}\text { Jumlah telur (butir)/ } \\
\text { Total eggs (grain) }\end{array}$ & $\begin{array}{c}\text { Jumlah tukik (ekor)/ } \\
\text { Total hutchling (tail) }\end{array}$ & $\begin{array}{c}\text { \% penetasan/ } \\
\text { \% spawning }\end{array}$ \\
\hline Maret & 2.806 & 2.724 & 97 \\
April & 2.693 & 2.573 & 96 \\
Mei & 2.929 & 2.929 & 100 \\
Juni & 2.710 & 2.710 & 100 \\
Juli & 2.404 & 2.404 & 100 \\
Agustus & 20.392 & 20.392 & 100 \\
September & 37.447 & 37.447 & 100 \\
\hline
\end{tabular}




\section{Perilaku Penyu Hijau}

\section{Proses bertelur}

Berdasarkan atas pengamatan penyu pada bulan Agustus 2008 waktu yang diperlukan untuk bertelur sekitar empat jam (pukul 19.00-24.00). Proses peneluran penyu hijau dibagi menjadi tahapan yaitu muncul ke permukaan laut dan memilih lokasi bertelur yang cocok, menggali lubang badan dan lubang telur, bertelur, menutup sarang, menutup lubang dan menyamarkan predator yang akan memangsa, dan akhirnya kembali ke laut (Tabel 5).

\section{Migrasi}

Penyu hidup beradaptasi dengan baik di lingkungan laut dan bernafas dengan paru-paru. Hampir seluruh siklus hidup penyu berlangsung di laut, penyu betina kembali ke pantai untuk meletakan telurnya. Jarak migrasi antara pencarian makan dan sarangnya di pantai cukup jauh, umur penyu 20-250 tahun dan penyu hijau dapat mencapai 100 tahun (Nuitja, 1992). 
Tabel 5. Proses tahapan bertelur penyu hijau di Pantai Pangumbahan Table 5. Process of green turtle spawning phase in Pangumbahan coast

\begin{tabular}{|c|c|c|}
\hline No. & Tahap/Stage & Uraian/Description \\
\hline 1. & $\begin{array}{l}\text { Muncul ke permukaan laut dan } \\
\text { memilih lokasi untuk bertelur } \\
\text { (searching phase) }\end{array}$ & $\begin{array}{l}\text { Penyu hijau muncul ke permukaan laut. Setelah merasa keadaan } \\
\text { aman, penyu bergerak ke daratan untuk mencari tempat yang } \\
\text { cocok untuk bertelur. Waktu yang diperlukan dalam tahapan ini } \\
\text { antara } 60-90 \text { menit. Penyu tidak lagi menghiraukan rintangan yang } \\
\text { ada dan bergerak terus ke arah tempat penelurannya. }\end{array}$ \\
\hline
\end{tabular}

2. Menggali lubang (digging phase)

Flipper depan bergerak lebih aktif menggali lubang badan dari pada pasangan flipper belakang. Penggalian berakhir bila telah mencapai kedalaman tertentu (mendapatkan tempat yang hangat) sekaligus badan terbenam rata di bawah permukaan pasir. Penggalian lubang telur dilakukan setelah membuat lubang untuk badan, flipper belakang bergerak secara periodik jika flipper kiri belakang menggali lubang telur, cara kerja flipper belakang mirip sebuah sekop, bila flipper kanan menggali lubang maka flipper kiri akan membuang hasil galian. Setelah mencapai kedalaman tertentu, penggalian dihentikan. Waktu yang digunakan dalam tahapan ini sekitar 20-40 menit. Bentuk lubang sarang seperti labu dengan kedalaman sekitar $30 \mathrm{~cm}$.

3. Bertelur (lying) Pada saat bertelur, kedua flipper belakang dirapatkan ke arah belakang menutup ekor yang dilipat ke depan menggantung di atas lubang telur. Selanjutnya telur dikeluarkan melalui cloaka dan diselubungi oleh lendir. Tahapan ini memerlukan waktu kurang lebih 20-25 menit, tergantung banyaknya jumlah telur yang dikeluarkan.

4. Menutup sarang (covering the Setelah telur dikeluarkan, lubang ditutup dengan flipper belakang nest)

dengan cara bergantian mengambil pasir disekitar lubang telur. Bila seluruh lubang telur telah berisi pasir, kedua flipper belakang menepuk-nepukan pasir di atas lubang sampai padat. Penutupan lubang badan dilakukan dengan cara melemparkan pasir terdekat ke lubang badan untuk menebalkan timbunan pasir. Tahapan ini memerlukan waktu kurang lebih 15-25 menit.

5. Menutup lubang dan Setelah sarang tertutup pasir, penyu hijau membuat sarang palsu menyamarkan jarak (filling body pit agar telur yang ditanam sulit ditemukan predator. Gerakan ini and concealing nect cit) dilakukan secara acak, terkadang berputar-berputar di sekitar sarang aslinya. Pembuatan sarang palsu merupakan yang terlama dari semua tahapan bertelur selama kurang lebih 60-120 menit.

6. Kembali ke laut ( return to the sea) Setelah kegiatan bertelur selesai, penyu kembali ke laut. Penyu akan berhenti beberapa kali di tepi batas pasang surut air laut dan menunggu datangnya ombak yang dapat membantu mendorong tubuhnya kembali ke laut. Tahapan ini memerlukan waktu 10-20 menit, tergantung jarak tempuh untuk sampai ke laut.

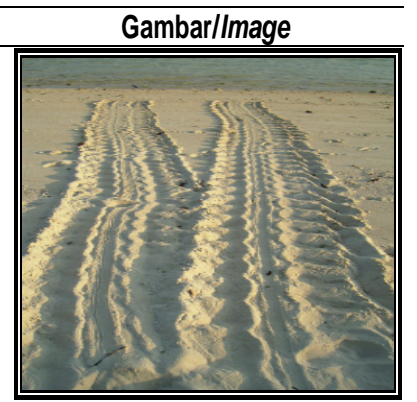

Jejak penyu dari laut ke tempat pembuatan sarang

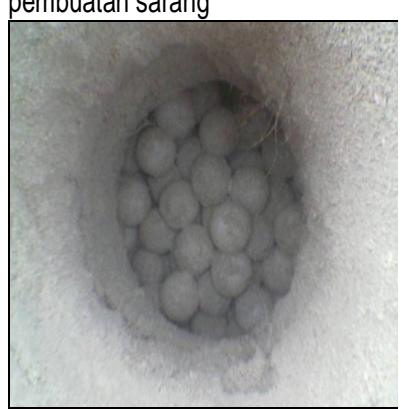

Telur penyu
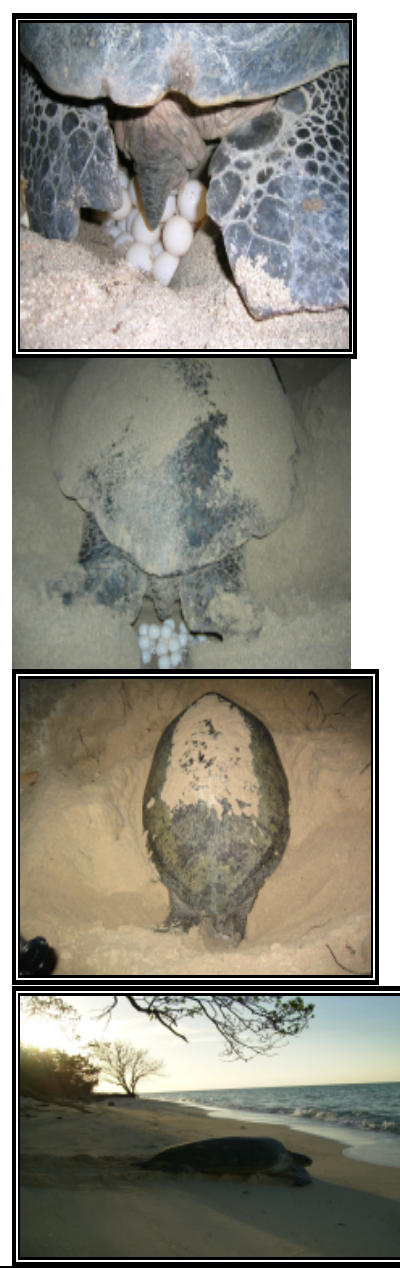


\section{Upaya Pelestariaan Penyu Hijau}

\section{Peneluran penyu hijau dengan sistem semi alami}

Penetasan penyu hijau di Pangumbahan secara semi alami (menggunakan ruangan yang sudah disiapkan) dilakukan dengan cara memindahkan telur penyu ke dalam wadah yang sudah berisi pasir dengan maksud telur mendapatkan kehangatan selama pengeraman. Untuk menjaga kualitas pasir maka dilakukan penggantian pasir setiap penetasan berakhir. Telur yang berasal dari satu ekor induk diletakan dalam satu wadah. Lama pengeraman sekitar 45-60 hari. Penetasan di luar ruangan (di pantai) mendapat banyak gangguan dari predator seperti ular, babi hutan, biawak, atau semut. Upaya mengurangi resiko gangguan yaitu dengan cara membuat pagar di sekeliling lubang atau sarang peneluran.

\section{Restocking tukik}

Tukik hasil penetasan telur selanjutnya diletakan dalam bak porselin yang sudah disediakan dengan media air laut dan diberi pakan buatan (pelet). Bila sudah berumur dua minggu diberi makanan berupa ikan rucah sampai saat dilaksanakan restocking (sekitar umur tiga bulan). Pengelola telah berhasil melakukan restocking tukik 71.179 ekor sejak bulan Maret sampai September 2008.

\section{KESIMPULAN}

1. Jumlah penyu hijau yang singgah ke Pantai Pangumbahan 89 ekor dan $50 \%$ di antaranya bertelur. Eksplotasi telur sudah tidak lagi dilakukan oleh masyarakat setempat semenjak dikelola oleh Dinas Perikanan dan Kelautan Kabupaten Sukabumi.

2. Panjang karapas penyu hijau berkisar antara 97$115 \mathrm{~cm}$ dengan lebar berkisar antara $83,5-108 \mathrm{~cm}$. Diameter telur berkisar antara 44-46 mm dengan bobot telur berkisar antara 50-52 g. Seekor induk penyu sekali bertelur antara 80-105 butir.

3. Total waktu untuk proses bertelur kurang lebih empat jam, berlangsung mulai pukul 19.00-24.00.

4. Kegiatan peneluran penyu hijau dibagi menjadi enam tahapan yaitu muncul ke permukaan laut dan memilih lokasi bertelur yang cocok, menggali lubang badan dan lubang telur, bertelur, menutup sarang, menutup lubang dan menyamarkan jarak, dan terakhir kembali ke laut.
5. Upaya pelestarian penyu hijau dilakukan dengan sistem semi alami melalui media penetasan. Dengan sistem tersebut berhasil ditetaskan pada bulan Maret sampai September 2008.

6. Disarankan restocking segera dilakukan setelah proses peneluran berlangsung agar tukik yang dihasilkan langsung beradaptasi dengan kondisi laut.

\section{PERSANTUAN}

Tulisan ini merupakan kontribusi dari kegiatan riset evaluasi konservasi penyu di pesisir selatan Jawa (Jawa Barat dan Banten), T. A. 2008, di Loka Riset Pemacuan Stok Ikan-Jatiluhur, Purwakarta.

\section{DAFTAR PUSTAKA}

Adnyana, W. 2006. Status of leatherback Indonesia. Indian Ocean and SE Asian Leatherback-Tsunami Assesment-February 2006 Draft. 50 pp. Diunduh melalui:http:/www.ioseaturtle.org/UserFies/File/ meeting_files/MT_IO4_DOCO9 tsunamai_report_Part3_

Indonesia-Oman.pdf. Pada Tanggal 30 Juli 2009.

Anonimus. 2008. Evaluasi konservasi penyu di pesisir selatan Jawa (Jawa Barat dan Banten). Laporan Akhir. Loka Riset Pemacuan Stok Ikan. Pusat Riset Perikanan Tangkap. Badan Riset Kelautan dan Perikanan. Departemen Kelautan dan Perikanan. $89 \mathrm{pp}$.

Dinas Kelautan dan Perikanan Kabupaten Sukabumi. 2008. Data Penyu Hijau (Jumlah Kehadiran Induk, Jumlah Telur) di Pantai Pangumbahan, Kabupaten Sukabumi.

Nastiti, A. S., Krismono, \& Wiadnyana, I. N. N. 2009. Evaluasi Sistem Konservasi Penyu Hijau (Chelonia mydas) di Pantai Pangumbahan Kabupaten Sukabumi, Provinsi Jawa Barat. Laporan Akhir Tahunan Program Intensif Peneliti dan Perekayasa Badan Riset Kelautan dan Perikanan Tahun 2009. $74 \mathrm{pp}$.

Nuitja. 1992. Biologi dan Ekologi Pelestarian Penyu Laut. Institut Pertanian Bogor. Bogor.

Purwa, D. G. D. 2010. Tujuh Jenis Penyu yang Dilindungi Undang-Undang. Diunduh melalui: http:/ /dymasgalih.wordpress.com/2010/01/04/7-jenispenyu-yang-dilindungi-undang-undang/. Pada Tanggal 31 Agustus 2010. 
Wahyudin, Y. 2004. Karakteristik Sumber Daya Pesisir dan Laut Kawasan Teluk Pelabuhan Ratu, Kabupaten Sukabumi. Program Studi Ekonomi Sumber Daya Kelautan Tropika. Sekolah Pasca Sarjana Institut Pertanian Bogor. Makalah sebagai Tugas Akhir Mata Kuliah Karakteristik Pengelolaan Sumber Daya Kelautan Tropika. 33 pp. Diunduh melalui:files.wordpress.com/.../20040123karakteristik-sumber daya-pesisir-dan-lautkawasan-teluk-pelabuhan ratu-kabupatensukabumi. Pada Tanggal 30 Juli 2009.
Yudha, S. 2004. Evaluasi pengelolaan pengunduhan telur penyu di Pantai Pangumbahan dan Tataniaga produknya di wilayah Sukabumi, Jawa Barat. Skripsi. Departemen Konservasi Sumber Daya Hutan. Fakultas Kehutanan. Institut Pertanian Bogor. 62 pp. 